\title{
Canadian Geotechnical Journal — Editors' Choices 2018
}

The Editor's Choice initiative by Canadian Science Publishing and the Canadian Geotechnical Journal is a means of highlighting articles of particularly high caliber and topical importance. Last year, the following papers were featured on the Journal's home page.

Centrifuge modeling of municipal solid waste landfill failures induced by rising water levels

Yun-min Chen, Jun-chao Li, Chun-bao Yang, Bin Zhu, and Liang-tong Zhan

54(12): 1739-1751 dx.doi.org/10.1139/cgj-2017-0046

Field behaviour of screw micropiles subjected to axial loading in cohesive soils

Zhengyang Guo and Lijun Deng

55(1): 33-44 dx.doi.org/10.1139/cgj-2017-0109

Undrained behaviour of intact soft clay under cyclic paths that match vehicle loading conditions

Lin Guo, Yuanqiang Cai, Richard J. Jardine, Zhongxuan Yang, and Jun Wang

55(1): 90-106 dx.doi.org/10.1139/cgj-2016-0636

One-dimensional large-strain thaw consolidation using nonlinear effective stress - void ratio - hydraulic conductivity relationships Simon Dumais and Jean-Marie Konrad

55(3): 414-426 dx.doi.org/10.1139/cgj-2017-0221

Determination of permeability of overconsolidated clay from pressuremeter pressure hold tests

Lang Liu, David Elwood, Derek Martin, and Rick Chalaturnyk

55(4): 514-527 dx.doi.org/10.1139/cgj-2017-0279

Behaviour of saturated railway track foundation materials during undrained cyclic loading

Anna Mamou, Jeffrey A. Priest, Christopher R.I. Clayton, and William Powrie

55(5): 689-697 dx.doi.org/10.1139/cgj-2017-0196

Geosynthetic reinforced column supported embankments and the role of ground improvement installation effects

Daniel J. King, Abdelmalek Bouazza, Joel R. Gniel, R. Kerry Rowe, and Ha H. Bui

55(6): 792-809 dx.doi.org/10.1139/cgj-2017-0036

Probabilistic seismic-hazard site assessment in Kitimat, British Columbia, from Bayesian inversion of surface-wave dispersion Jeremy M. Gosselin, John F. Cassidy, Stan E. Dosso, and Camille Brillon

55(7): 928-940 dx.doi.org/10.1139/cgj-2017-0265

Effect of various treatments on consolidation of oil sands fluid fine tailings

G. Ward Wilson, Louis K. Kabwe, Nicholas A. Beier, and J. Don Scott

55(8): 1059-1066 dx.doi.org/10.1139/cgj-2017-0268

Effective friction angle of clays and silts from piezocone penetration tests

Zhongkun Ouyang and Paul W. Mayne

55(9): 1230-1247 dx.doi.org/10.1139/cgj-2017-0451

Development of a prototype for modelling soil-pipe interaction and its application for predicting uplift resistance to buried pipe movements in sand

Yousef Ansari, George Kouretzis, and Scott W. Sloan

55(10): 1451-1474 dx.doi.org/10.1139/cgj-2017-0559

Laboratory piping tests on fine gravel

Bryant A. Robbins, Isaac J. Stephens, Daniel A. Leavell, Jamie F. López-Soto, and Axel M. Montalvo-Bartolomei

55(11): 1552-1563 dx.doi.org/10.1139/cgj-2016-0350 